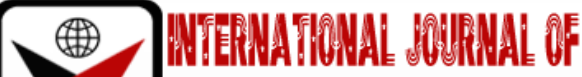

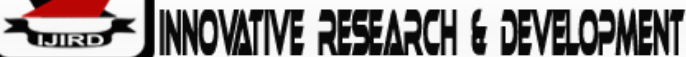

ISSN 2278-0211 (Online)

\section{Uptake of Health Insurance Schemes Accessible to the Informal Sector Workers in Vihiga Sub County, Vihiga County, Kenya: A Cross Sectional Study}

\begin{tabular}{|c|}
\hline $\begin{array}{c}\text { Muranda Marion Agiza } \\
\text { Student, School of Health Sciences, } \\
\text { Jaramogi Oginga Odinga University of Science and Technology, Bondo, Kenya } \\
\text { Owenga Jane Adhiambo } \\
\text { Lecturer, School of Health Sciences, } \\
\text { Otieno David Odongo } \\
\text { Jaramogi Oginga Odinga University of Science and Technology Bondo, Kenya } \\
\text { Work Nairobi, Kenya } \\
\text { Lecturer, In-Depth Research Services Institute of Health and Social } \\
\text { Onguru Daniel Ogungu } \\
\text { Lecturer, School of Health Sciences, } \\
\text { Orende Marceline Awino } \\
\text { Jaramogi Oginga Odinga University of Science and Technology Bondo, Kenya } \\
\text { Student, School of Health Sciences, } \\
\text { Owuramogi Oginga Odinga University of Science and Technology, Bondo, Kenya } \\
\text { Owuocha Dorice Akoth } \\
\text { Student, School of Health Sciences, } \\
\text { Ojwang Hellen Atieno } \\
\text { Jaramogi Oginga Odinga University of Science and Technology, Bondo, Kenya } \\
\text { Student, School of Health Sciences, } \\
\text { Jaramogi Oginga Odinga University of Science and Technology, Bondo, Kenya }\end{array}$ \\
\hline
\end{tabular}

\begin{abstract}
:
Health insurance increases access to healthcare services and improves financial risk protection. The objective of the study was to determine uptake of health insurance schemes accessible to the informal sector workers in Vihiga Sub County. A descriptive cross sectional study design was adopted to collect data. The target population for the purpose of this study was the informal sector workers from Vihiga Sub County drawn from the four wards in the Sub County. Sampling was done using cluster sampling and simple random sampling techniques, to obtain a representative sample of 384; Data was collected using semi-structured questionnaires and analyzed using descriptive statistics and chisquare test used to test for association ( $p<0.05)$. Health insurance coverage in the sample was 132(34.38\%). The accessibility of public health insurance scheme (NHIF) in Vihiga Sub-County was found to be $40.10 \%$ (95\%CI=0.35 0.45). The Private health insurance schemes accessible to the informal sector were few and cash payment was the main mode of clearing hospital bills. The result revealed that there was no significant association between monthly payment of health insurance and default rate in Vihiga Sub-County (p-value>0.05). Private Health Insurance schemes should be designed in such a way that they accommodate the low-income groups. Sensitization of the community by these insurance schemes this ensures there is increased penetration in the rural settings. Health insurance has not been fully exploited as a way of reducing financial constraints.
\end{abstract}

Keywords: Health Insurance, National Health Insurance Fund (NHIF), informal sector, health insurance schemes

\section{Introduction}

The way in which a health care system operates determines whether people can afford to use health care services when they are in need. A high proportion of the world's 1.3 billion poor have no access to health services because they cannot afford to pay (Acharya et al., 2012). Good health is essential to human welfare and to sustained economic and social development. WHO Member States set the target of developing health financing systems such that all people can use health services, while being protected against financial hardship associated with paying for them (WHO, 2010). Health insurance 
is attracting more attention in LMICs as a way of improving health care utilization reducing catastrophic health expenditures and protecting households against impoverishment (Spaan et al., 2012).

The history of health insurance has evolved internationally; different countries have been utilizing various models of insurance and financing schemes to pay for medical services. There are three salient categories of health insurance but they vary for each category and some countries (Ho, 2015). Several LMICs, are establishing Social Health Insurance (national health insurance) which is based on mandatory enrolment. Voluntary insurance mechanisms include private health insurance (PHI) that serves the affluent segments of a population, and community-based health insurance (CBHI) that benefits the poor (Spaan et al., 2012).

Germany's Health care is financed through state and private health insurance schemes (Döring \& Paul, 2010). Government regulates Private health insurance scheme in Germany, this ensures the insured do not face high premium rates as they age and are not overburdened by premiums if their income decreases (Busse \& Blümel, 2014; Fong et al., 2016).China's public health insurance system is covers the largest population in the world (95\%) but has limited financial protection. Private health insurance is available, targets the high-income population and has remained slow in its development (Jin et al., 2016). India with more than one national health insurance scheme; has experienced health inequalities due to insufficient state spending and establishment of a large unregulated private sector (Jain, 2013).Private insurance in India is mostly purchased for financial protection against catastrophic health expenses (Dutta \& Hongoro, 2013).

There are various types of insurance approaches that are being used in SSA (Welcome, 2011). The Nigerian health insurance scheme (NHIS) initially covered formal sector employees (40\%) of the population while about $60 \%$ in the informal sector was not reached. Exclusion of the informal sector led to the scheme's expansion and inclusion of CBHI (Eboh et al., 2016). In Tanzania, for the formal sector, the largest scheme is the NHIF currently reaching out to members of the private formal sector. For the informal sector, the Community Health Fund (CHF) is the largest scheme operating in rural districts (Borghi et al., 2012).

Health insurance in Kenya can be accessed through: public health insurance scheme- the National Health Insurance Fund (NHIF) with a mandatory membership to those working in the formal sector and voluntary for those working in the informal sector, Private health insurance which comprises of the wealthiest population and is highest in the urban areas (Chuma \& Okungu, 2011). CBHI established in 1999 in Kenya, was initiated through donor support this made them an alternative cover for the informal sector, they are not widespread (Kimani et al., 2012; Mulupi et al., 2013) . Most of them discontinued operations since they were not sustainable following withdrawal of donor funds (Chuma \& Okungu, 2011). They operate in rural areas and are relatively small, thereby undermining the potential for risk pooling and crosssubsidization. CBHI also have small size contributions that are inadequate; lack mechanisms for assessing quality of care offered this undermines their efficiency and absence of negotiated fee schedules makes it difficult to determine reimbursements (Eboh et al., 2016).

In Kenya only about $10 \%$ have health insurance with high coverage among the richest (26.4\%) compared to the poorest population (1.9\%) (Chuma \& Okungu, 2011). Kenya has made attempts towards universal health insurance but lack of sustainable health financing mechanisms has made it impossible to implement SHI programmes(Kimani et al., 2012). Kenya's predominantly tax-funded health system, has gradually undergone a series of health financing policy changes (Muiya \& Kamau, 2013). Most policies have negatively affected health care provision, mostly the cost-sharing programme, an indication that health financing in Kenya has faced numerous challenges, including inadequate funding which results to increased out-of-pocket spending for healthcare and ultimately this negatively affects acquisition of health care (Deolitte, 2011). Strong emphasis has been placed on the necessity of developing insurance schemes, since reforms in healthcare have shifted the burden of health care financing from government to patients and this has a negative impact on health care utilization (Muiya \& Kamau, 2013).

Our study sort to determine the uptake of health insurance schemes accessible to the informal sector workers particularly in Vihiga Sub County. This study used a cross sectional study design. Findings from this study will enhance the transformation of health insurance schemes; to better accommodate all persons, including the poor and vulnerable, and increase access to quality and affordable health care services.

\section{Materials and Methods}

This was a descriptive cross- sectional study design on uptake of health insurance schemes in Vihiga Sub-county. The target population for the purpose of this study was the informal sector workers from Vihiga Sub County, however data on informal sector workers in Vihiga Sub County is not known and given the fact that the sub-county is majorly rural the researcher therefore used data of the employment population in Vihiga Sub-County. According to(KNBS \& SID, 2013) the population in working ages is in the age group of 15-64 years. The required sample size of 384 was calculated using Fischer's formula. Sampling was done using cluster sampling and simple random sampling techniques. Cluster sampling was done by ward and a co- efficient of variation used to calculate the sample that was used from each ward. Simple random sampling was then applied where participants were selected randomly. Data collection was done by trained research assistants using semi- structured questionnaires. The descriptive statistics were organized and summarized using tables and charts, while Chi-square test was used to detect for association among study variables. Ethical approval to carry out the study was sought from the Ethical Review Committee at Jaramogi Oginga Odinga Teaching and Referral Hospital, the license to conduct the study was Obtained from national commission for Science, technology \& innovation (License No: NACOSTI/P/20/4927). Permission to conduct the study was sought from the relevant county, sub county and local authorities. The respondents were assured that the purpose of the study was basically academic and that all the information given will be treated with confidentiality. 


\section{Results}

It is revealed in Table 1 that majority 252 (65.63\%) of the respondents did not enroll for national health insurance in Vihiga (95\%CI=0.61 - 0.70) and 132(34.38\%) enrolled for national health insurance (95\%CI=0.30 - 0.40). This section represents the pattern and the distribution of health insurance schemes accessible for uptake among informal sector workers in Vihiga Sub-County. The accessibility of NHIF in Vihiga Sub-County was found to be $40.10 \%$ (95\%CI=0.35 $0.45)$ since out of 384 respondents in this study, 154(40.10\%) reported that NHIF was accessible to them, 47(12.24\%) $(95 \% \mathrm{CI}=0.09-0.16)$ were able to access Jubilee health insurance, the accessibility of Britam was found to be $45(12.5 \%)$ (95\%CI=0.10 - 0.16), 29(7.55\%) were able to access Co-operative Insurance Company (CIC), 22(5.73\%) (95\%CI=0.05 0.11) were able to access health insurance services from AON insurance company. Apollo and Pan Africa (APA) was also one of the available health insurance companies in Vihiga Sub-County. The result in Table 2shows that 19(4.95\%) $(95 \% \mathrm{CI}=0.03-0.08)$ of the total respondents said that APA was accessible to them. Linda jamii which is one of the local health insurance schemes was also accessible to $12(3.13 \%)$ of the total respondents. The accessibility of the other health insurance schemes was $9(2.34 \%), 6(1.56 \%)$ and $6(1.56 \%)$ for Madison, Medicare and AAR, respectively. However, the proportion of the respondents who were not able to access any health insurance scheme was found to be $9.11 \%$ $(95 \% \mathrm{CI}=0.07-0.12)$

\subsection{Association between monthly Premium and Default Rate}

Table 3: below shows the level of association between monthly premium and default rate of those who take health insurance. A chi-square test was done to show the level of significance at $95 \%$ confidence interval. Out of 132 respondents who were paying monthly premium, majority $100(76.47 \%)$ were paying between KSh 500 to 1000 . However, 25(25.00\%) of them defaulted payment and were not able to access health insurance services. There were 11(8.09\%) respondents who were paying less than KSh. 500 and 4(36.36\%) of them defaulted payment.

The result reveal that there is no significant association between monthly payment of health insurance scheme and default rate in Vihiga Sub-County ( $p$-value $>0.05$ ).

\subsection{Introduction to the Health Insurance Scheme}

From the analysis, 52(39.39\%) of the 132 enrolled respondents were introduced to the scheme by their family members/relative, $38(28.79 \%)$ being introduced by a friend, $6(4.55 \%)$ were introduced by insurance agent, $6(4.55 \%)$ were introduced by healthcare providers and $30(22.72 \%)$ took up the schemes on their own. Figure 1 summarizes the responses

\subsection{Duration of Enrollment in Health Insurance}

Among the 132 respondents that had been enrolled on health insurance, majority $85(64.39 \%)$ had been in health insurance for 2 to 4 years, $19(14.39 \%)$ had been in health insurance for one year or less and 28(21.21\%) had been in health insurance for a period of five years and above. Figure 2

\subsection{Admission to the Hospital}

Figure 3 reveals that majority 225(58.59\%) of the respondents had not been admitted in hospital for the past 12 months and $159(41.41 \%)$ had been sick and admitted to the hospital for a period of one year before the data was collected.

\subsection{Mode of Payment of Hospital Bill}

In Figure 4, Out of the 159(41.41\%) who had ever been admitted in the hospital in the last 12 months, 61(38.36\%) settled their hospital bill through insurance and 98(61.64\%) settled their hospital bill using cash.

\section{Discussion}

When compared to private insurance schemes, National Hospital insurance Fund (NHIF) had more popularity since 154(40.10\%) respondents reported that NHIF was accessible to them. This high accessibility of NHIF can be attributed to its affordability and acceptability in all government and private hospitals. In many countries, Private Health Insurance (PHI) has been predominantly purchased by high-income groups, however the private insurance market does not provide sufficient financial protection and are not accessible for people with the greatest need (Odeyemi \& Nixon, 2013). Income levels remain low among the informal sector, resulting in low participation in programs and schemes such as health insurance and most importantly the private health insurance schemes

The private health insurance companies that respondents said were accessible to them are Britam, CIC, AAR, Madison AON, APA, Linda jamii, Medicare, Madison and jubilee, this list does not encompass all the companies that offer private insurance to the informal sector given their massive numbers. Private insurance companies are mostly located in urban areas and do not have countrywide coverage(MoH \& GoK, 2014). There is need for these companies to sensitize the community and ensure there is increased penetration in the rural settings that will result to maximum coverage with regards to insurance in the informal sector.

With regards to premium payment and default rate, majority $100(76.47 \%)$ of the respondents were paying between KSh 500 to 1000 . However, 25(25.00\%) of them defaulted payment and were not able to access health insurance services. There were $11(8.09 \%)$ respondents who were paying less than KSh. 500 and $4(36.36 \%)$ of them defaulted payment. The results reveal that there is no significant association between monthly payment of health insurance and default rate in Vihiga Sub-County. Some of the challenges that can be attributed to payment of premiums are lack of finance. According to (Mulupi et al., 2013)access to cash in many rural areas and in the informal sector is seasonal and 
making sure that timing for making contributions correspond with peak seasons when people have access to most of their annual income could improve on affordability and sustainability of premiums.

The results from the study show that 61(38.36\%) of the respondents settled their hospital bill through insurance and 98(61.64\%) settled their hospital bill using cash. (Eboh et al., 2016) noted that healthcare financing across the less developed and developing countries is still characterized by OOP health expenditure. The above result implies that the use of cash to pay reinforces the fact health insurance has not been fully exploited as a way of reducing financial constraints and that the major barrier in accessing healthcare services to the less privileged persons in the society is lack of finances.

\section{Conclusion}

Private Health Insurance schemes should be designed in such a way that they accommodate the low-income groups. Sensitization of the community by these insurance schemes this ensures there is increased penetration in the rural settings. Health insurance has not been fully exploited as a way of reducing financial constraints.

\section{Declaration of Interests}

The authors declare no competing interests

\section{Acknowledgement}

- The University ofJaramogi Oginga Odinga University of Science \& Technology, the supervisors.

- The Medical Officer of health.

- Research assistants for data collection.

- The respondents for accepting to participate.

\begin{tabular}{|c|c|c|c|}
\hline & $\begin{array}{c}\text { Proportion } \\
\mathrm{n}(\%)\end{array}$ & Std. Err. & $95 \%$ C I \\
\hline Enrolment of NHI & & & \\
\hline No & $252(65.63)$ & 0.024269 & $0.61-0.70$ \\
\hline Yes & $132(34.38)$ & 0.024269 & $0.30-0.40$ \\
\hline
\end{tabular}

Table 1: Proportion of National Health Insurance Uptake

\begin{tabular}{|c|c|c|}
\hline Health insurance scheme & Frequency (\%) & 95\%confidence level \\
\hline NHIF & $154(40.1)$ & $0.35-0.45$ \\
\hline Jubilee & $47(12.24)$ & $0.09-0.16$ \\
\hline Britam & $45(11.75)$ & $0.10-0.16$ \\
\hline CIC & $29(7.55)$ & $0.05-0.11$ \\
\hline AON & $22(5.73)$ & $0.04-0.09$ \\
\hline APA & $19(4.95)$ & $0.03-0.08$ \\
\hline Linda jamii & $12(3.13)$ & $0.02-0.04$ \\
\hline Madison & $9(2.34)$ & $0.01-0.04$ \\
\hline Medicare & $6(1.56)$ & $0.01-0.03$ \\
\hline AAR & $6(1.56)$ & $0.01-0.03$ \\
\hline Not accessible to any scheme & $35(9.11)$ & $0.07-0.12$ \\
\hline
\end{tabular}

Table 2: Accessibility of Health Insurance Schemes among Informal Sector Workers in Vihiga Sub-County

\begin{tabular}{|c|c|c|c|c|}
\hline & & \multicolumn{2}{|c|}{ Default } & \\
\hline Monthly premium & N (\%) & No n (\%) & Yes n (\%) & p-value \\
\hline$<500$ & $11(8.09)$ & $7(63.64)$ & $4(36.36)$ & 0.228 \\
\hline $500-1000$ & $100(76.47)$ & $75(75.00)$ & $25(25.00)$ & \\
\hline $1001-2500$ & $10(7.35)$ & $10(100.00)$ & $0(0.00)$ & \\
\hline $2501-5000$ & $4(2.94)$ & $4(100.00)$ & $0(0.00)$ & \\
\hline$>5000$ & $7(5.15)$ & $5(71.43)$ & $2(28.57)$ & \\
\hline Total & $132(100.00)$ & $101(76.52)$ & $31(23.48)$ & \\
\hline
\end{tabular}

Table 3: Level of Association between Monthly Premium and Default Rate 


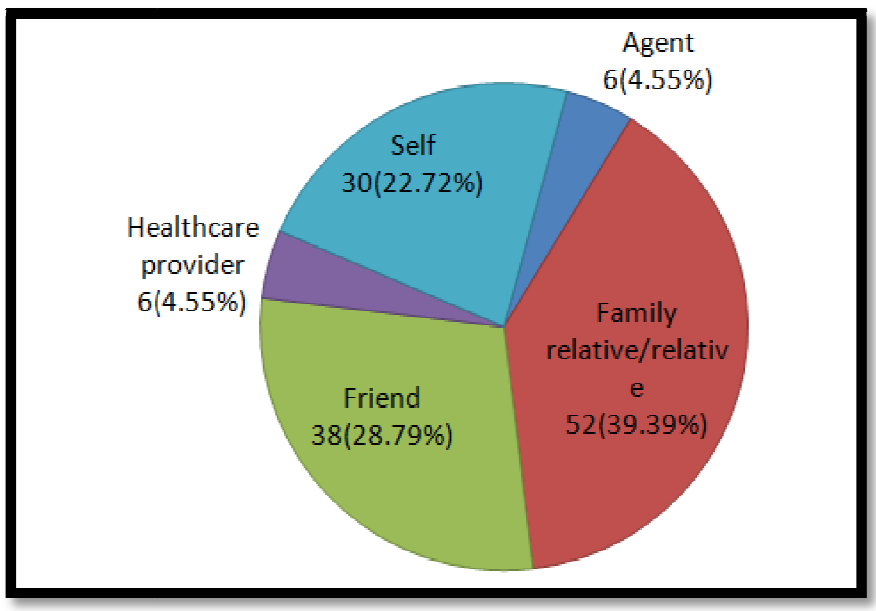

Figure 1: Introduction to Health Insurance Scheme

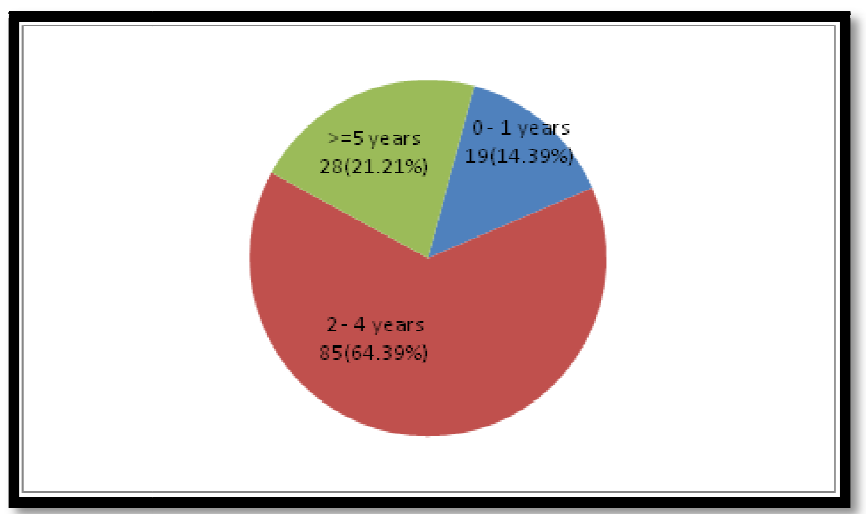

Figure 2: Duration of Enrollment in Health Insurance

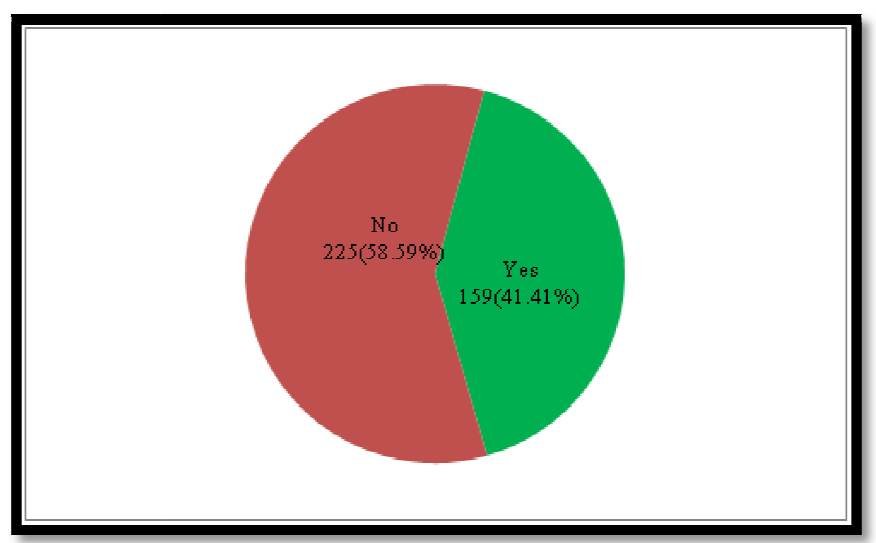

Figure 3: Admission to the Hospital in the Last 12 Months

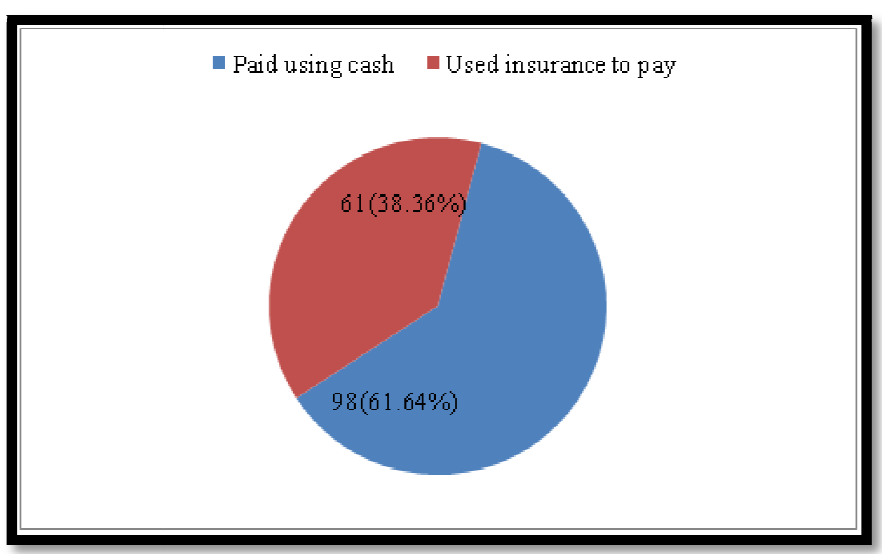

Figure 4: Mode of Payment of Hospital Bill 


\section{References}

i. Acharya, A., Vellakkal, S., Taylor, F., Masset, E., Satija, A., Burke, M., \& Ebrahim, S. (2012). Impact of national health insurance for the poor and the informal sector in low-and middle-income countries. London: The EPPI-Centre.

ii. Borghi, J., Mtei, G., \& Ally, M. (2012). Modelling the implications of moving towards universal coverage in Tanzania. Health policy and planning, 27(suppl_1), i88-i100.

iii. Busse, R., \& Blümel, M. (2014). Germany. Health system review.

iv. Chuma, J., \& Okungu, V. (2011). Viewing the Kenyan health system through an equity lens: implications for universal coverage. Int J Equity Health, 10(1), 22.

v. Deolitte, C. (2011). A strategic review of NHIF and market assessment of private prepaid health schemes. Nairobi: Ministry of Medical Services.

vi. Döring, A., \& Paul, F. (2010). The German healthcare system. EPMA Journal, 1(4), 535-547.

vii. Dutta, A., \& Hongoro, C. (2013). Scaling up national health insurance in Nigeria: learning from case studies of India, Colombia, and Thailand. Washington, DC: Futures Group The Health Policy Project.

viii. Eboh, A., Akpata, G., \& Akintoye, A. (2016). Health Care Financing in Nigeria: An Assessment of the National Health Insurance Scheme (NHIS). European Journal of Business and Management, 8(27), 24-34.

ix. Fong, B. Y., Kan, M. H., Ho, H. S., \& Leung, H. (2016). Universal health care in Hong Kong: lessons from.

x. Ho, A. (2015). Health Insurance. Encyclopedia of Global Bioethics, 1-9.

xi. Jain, K. (2013). Health financing and delivery in India: An overview of selected schemes. Women in Informal Employment Globalising and Organising (WIEGO) Working Paper No, 29, 28.

xii. Jin, Y., Hou, Z., \& Zhang, D. (2016). Determinants of Health Insurance Coverage among People Aged 45 and over in China: Who Buys Public, Private and Multiple Insurance. PLoS One, 11(8), e0161774.

xiii. Kimani, J. K., Ettarh, R., Kyobutungi, C., Mberu, B., \& Muindi, K. (2012). Determinants for participation in a public health insurance program among residents of urban slums in Nairobi, Kenya: results from a cross-sectional survey. BMC Health Serv Res, 12, 66.

xiv. KNBS, \& SID. (2013). Exploring Kenya's Inequality; Vihiga County, Pulling Apart or Pulling Together. Nairobi: KNBS, SID.

xv. MoH, \& GoK. (2014). 2013 Kenya Household Health Expenditure and Utilisation Survey. . Nairobi

xvi. Muiya, B. M., \& Kamau, A. (2013). Universal health care in Kenya: Opportunities and challenges for the informal sector workers. International Journal of Education and Research, 1(11), 1-10.

xvii. Mulupi, S., Kirigia, D., \& Chuma, J. (2013). Community perceptions of health insurance and their preferred design features: implications for the design of universal health coverage reforms in Kenya. BMC Health Serv Res, 13, 474.

xviii. Odeyemi, I., \& Nixon, J. (2013). The role and uptake of private health insurance in different health care systems: are there lessons for developing countries? ClinicoEconomics and outcomes research: CEOR, 5, 109.

xix. Spaan, E., Mathijssen, J., Tromp, N., McBain, F., Have, A. t., \& Baltussen, R. (2012). The impact of health insurance in Africa and Asia: a systematic review. Bulletin of the World Health Organization, 90, 685-692.

xx. Welcome, M. O. (2011). The Nigerian health care system: Need for integrating adequate medical intelligence and surveillance systems. J Pharm Bioallied Sci, 3(4), 470-478.

xxi. WHO. (2010). Administrative costs of health insurance schemes: Exploring the reasons for their variability. Geneva: World Health Organization. 